\title{
DA FORMAÇÃO CONTINUADA À EXTENSÃO: INTERFACES DA GAMIFICAÇÃO EM PROJETOS UNIVERSITÁRIOS
}

\author{
CAMPINAS/SP JULHO/2018
}

\author{
Fernanda de Oliveira Soares Taxa - PUC-CAMPINAS - fernanda.amaro@puc-campinas.edu.br \\ Victor Kraide Corte Real - PUC-CAMPINAS - realvic@gmail.com \\ Geraldo Magela Severino Vasconcelos - PUC-CAMPINAS - geraldo.magela@gmail.com \\ Juliana Signori Baracat Zeferino - PUC-CAMPINAS - baracat82@gmail.com \\ Patrícia Baston Frenhani - PUC-CAMPINAS - patfrenhani@gmail.com \\ Cyntia Belgini Andretta - PUC-CAMPINAS - cyntiaandretta@puc-campinas.edu.br \\ Nelson de Carvalho Mendes - PUC-CAMPINAS - nelson@puc-campinas.edu.br \\ Alex Itiro Shimabukuro - PUC-CAMPINAS - shima@puc-campinas.edu.br \\ Edmar Roberto Santana de Rezende - PUC-CAMPINAS - edmar_rezende@puc-campinas.edu.br
}

Tipo: Investigação Científica (IC)

Natureza: Descrição de Projeto em Andamento

Categoria: Métodos e Tecnologias

Setor Educacional: EDUCAÇÃO SUPERIOR

\begin{abstract}
RESUMO
Relacionar jogos e educação não é uma discussão inédita, uma vez que sua história é anterior ao surgimento dos jogos eletrônicos; e neste contexto, a gamificação não significa necessariamente criar games para desenvolver a aula, mas sim, usar a sua lógica para a prática pedagógica do docente universitário. A opção e o empenho em produzir trilhas de aprendizagem como uma das possibilidades de formação continuada virtual in loco de docentes universitários têm evidenciado a necessidade para novas investigações acerca da docência, da prática pedagógica e de metodologias ativas na formação pós-profissional de professores e de alunos para o século XXI. A abrangência e foco são ainda maiores, pois o cenário social da docência contemporânea vive, efetivamente um período de pósprofissionalismo e a formação continuada de docentes em nível superior deve estar em consonância com uma linha de estudos da extensão universitária, uma vez que os compromete ao diálogo efetivo entre a instituição e sua comunidade. $O$ artigo objetiva analisar os dados obtidos quanto a duas subetapas cursadas por professores de uma universidade particular do Estado de São Paulo/Brasil no curso de gamificação das trilhas de aprendizagem, apresentando ainda, o delineamento de um curso de extensão em gamificação inspirado nos saberes organizados por um docente da referida instituição. Trata-se de uma pesquisa qualitativa com método misto de análise. Participaram, inicialmente,35 docentes em um curso de gamificação oferecido no formato virtual. Os resultados obtidos apontam que a temática sobre gamificação pode ampliar os conhecimentos e perspectivas de atuação pedagógica dos professores, sejam elas na docência e/ou na modalidade de extensão universitária.
\end{abstract}

Palavras-chave: trilhas de aprendizagem;formação continuada;universidade;extensão;gamificação.

\section{AGRADECIMENTOS}

AGRADECEMOS O APOIO DA PRÓ-REITORIA DE 


\section{Introdução}

Em educação, usamos jogos há bastante tempo, como os de tabuleiro, jogos de cartas, as palavras cruzadas, os jogos populares, entre outros para potencializar os processos de ensino e de aprendizagem dos estudantes. A introdução da gamificação na educação implica revisão dos processos e paradigmas educacionais, e aqui, em particular, situações gamificadas que podem ser produzidas e usadas pelos docentes universitários com a finalidade de potencializar a aprendizagem dos estudantes em processo de formação acadêmica e profissional.

Relacionar jogos e educação não é uma discussão inédita, uma vez que sua história é anterior ao surgimento dos jogos eletrônicos; e neste contexto, a gamificação não significa necessariamente criar games para desenvolver a aula, mas sim, usar a sua lógica para a prática pedagógica do docente universitário. Nesse cenário, a docência, em especial, no ensino superior tem requerido do professor a mobilização de uma série de saberes que emerjam das múltiplas formas de interação (social, cultural, individual, material entre tantas outras) que ele possui, do mergulho às diferentes fontes que envolvam seus saberes.

A literatura sobre a formação de professores é vasta e não pretencionamos aqui, esgotar o assunto. Entretanto, um recorte possível sobre a temática nos remete à análise de Cunha e Prado (2010, p.104) quando, estes, defendem a formação continuada "centrada" na escola. Tal processo requer voltá-lo para a reflexão sobre a prática do professor. Para os autores "os sistemas escolares precisam pensar as inovações na perspectiva da instituição, favorecendo situações que permitam aprender a pensar e agir de forma diferente, enriquecendo, reconstruindo e reorientando a cultura profissional dos professores" (CANÁRIO, 1996, apud CUNHA; PRADO, 2010, p.104).

A opção e o empenho em produzir trilhas de aprendizagem como uma das possibilidades de formação continuada virtual inloco de docentes universitários têm evidenciado a necessidade para novas investigações acerca da docência, da prática pedagógica e de metodologias ativas na formação pós-profissional de professores e de alunos para o século XXI.

Coadunado as iniciativas de formação continuada em serviço na perspectiva virtual por meio das trilhas de aprendizagem em gamificação não poderíamos deixar de considerar, todavia, que o nível de abrangência é maior ainda; ou seja, o cenário social da docência contemporânea vive, efetivamente um período de pós-profissionalismo. A este respeito, Martins, Dias e Filho (2016, p.244) analisam o fenômeno e destacam a necessidade de ampliarmos e aprofundarmos a aprendizagem sobre "as relações pais-professores, 
professores-alunos e escola-comunidade".

Desse mote, ressaltamos, então, que a formação continuada de docentes em nível superior deva estar em consonância com uma linha de estudos da extensão universitária, uma vez que os compromete ao diálogo efetivo entre a instituição e sua comunidade. E, quando a formação continuada dos docentes em trilhas de aprendizagem potencializa projetos de extensão em que se pesem um "processo educativo, cultural e científico que articula o Ensino e a Pesquisa de forma indissociável e viabiliza a relação transformadora entre Universidade e Sociedade[...] então, podemos configurar, de fato, a Extensão como esta "via de mão-dupla, com trânsito assegurado à comunidade acadêmica, que encontrará, na sociedade, a oportunidade de elaboração da práxis de um conhecimento acadêmico.[...] (UFMG, 2012, s/n).

Quando buscamos aproximar os princípios da gamificação na formação do docente universitário destacamos aqui a transversalização que este saber pode acarretar em outros projetos (extensão) da universidade.

Este artigo objetiva analisar os dados obtidos quanto a duas subetapas cursadas por professores de uma universidade particular do Estado de São Paulo/Brasil no curso de gamificação das trilhas de aprendizagem, apresentando ainda, o delineamento de um curso de extensão em gamificação inspirado nos saberes organizados por um docente da referida instituição.

\section{Gamificação nas Trilhas de Aprendizagem - um curso na perspectiva virtual}

As trilhas de aprendizagem são sequências de atividades elaboradas em diferentes mídias com o objetivo de serem complementares entre si e de construírem o conhecimento a respeito de um tema. As atividades abrangem diferentes estilos de aprendizagem, formatos de conteúdo e representam, ainda, instrumento pelo qual o docente pode potencializar sua própria aprendizagem, podendo enriquecer suas práticas pedagógicas construídas com autonomia

O presente artigo aborda dados de um curso de gamificação das trilhas de aprendizagem cujo intuito, primeiramente, era 0 de levar o docente universitário a compreender que a gamificac?a?o e? um processo que usa elementos, meca?nicas e dina?micas de jogos para engajar e direcionar comportamentos de jogadores dentro de um contexto de não jogo.

O termo "gamificação" ganhou notoriedade a partir de 2010, durante uma apresentação de TED (Technology, Entertainment, Design) realizada por J. McGonigal, importante 
game designer norte-americana, mas o primeiro registro de uso do termo é referenciado ao pesquisador britânico e programador de computadores, Nick Pelling (MEDINA, 2013).

Mattar (2010), ao explicitar sobre a relação entre games e educação sinaliza que as fronteiras entre trabalho, diversão e aprendizagem vêm desaparecendo, uma vez que as novas experiências advindas das tecnologias têm permitido aprender muitas coisas e a qualquer momento. $O$ autor ressalta que os jogos são

\footnotetext{
[...] dispositivos de ensino e treinamento efetivos para alunos de qualquer idade, e em muitas situações, porque são altamente motivadores e comunicam muito eficientemente conceitos e fatos em muitas áreas. Eles criam representações dramáticas do problema real estudado. Os jogadores assumem papeis realistas, encaram problemas, formulam estratégias, tomam decisões e recebem feedback rápido da consequência de suas ações. [...] ensinam uma série de habilidades e possibilitam o aprendizado com a colaboração de colegas (MATTAR,2010,p. XX).
}

Os jogos, especificamente os digitais, podem ser encarados como sistemas em que situações reais são substituídas por situações lúdicas, fazendo que os jogadores percebam modelos e simulações da realidade (KUTOVA, OLIVEIRA, 2006, p.233).

Jogos em formato digital tendem a promover novas formas de produzir e difundir o conhecimento, congregando processos fundamentais de socialização do indivíduo e da formação de sua personalidade; e isto potencializa a criação experimental lúdica no meio digital. A este respeito, Martins e Giraffa (2015) lembram que a cultura lúdica se imbrica à cibercultura e enfatizam que [...] A onipresença das TD nesse contexto sociocultural, assim como o movimento natural dos jogos, suscitando a disseminação dos jogos digitais e da gamificação nas práticas cotidianas, acabam refletindo nas discussões que abarcam o uso de recursos tecnológicos em sala de aula (MARTINS; GIRAFFA, 2015,p.50).

Alguns dos elementos presentes na mecânica dos games são aplicados como princípios da gamificação: narrativa, desafio, conflito, cooperação, objetivos, níveis, regras claras, tentativa e erro, sistema de feedback e recompensa, diversão e interação (SALEN; ZIMMERMAN, 2012; McGONIGAL, 2011), ou seja, são criadas situações capazes de mobilizar e engajar um determinado público para realizar ações específicas e/ou assimilar de conteúdos de forma lúdica. Aplicar o modelo de elementos de jogos digitais em atividades gamificadas são iniciativas necessárias e cruciais para auxiliar e readequar práticas pedagógicas ao contexto sociocultural da cibercultura.

\subsection{0 curso gamificação nas trilhas de aprendizagem}

Os primeiros cursos das trilhas de aprendizagem correspondem ao eixo das metodologias ativas: PBL (problem-based learning), flipped classroom, 
portfólio e gamificação. Os diferentes cursos apresentam a seguinte estrutura: a) Guia do Curso; b) Aula Inaugural; c) E-books; d) Links úteis; e) Videoaulas; f) Mural de práticas docentes; g) Quiz conceitual e h) Escala de percepção docente do uso do espaço virtual para a aprendizagem. Entre um curso e outro há elementos adicionais que foram incorporados em função do próprio conteúdo do curso que necessitava de outros recursos. Os recursos do curso gamificação sofreram algumas alterações necessárias à temática, conforme apontamos abaixo.

O curso gamificação inicia convidando o docente a jogar o "Game: Caça às Estrelas", elaborado no Scratch que é um programa desenvolvido pelo MIT (Instituto Tecnológico de Massachussets) para criação de sequências animadas e dentre várias possibilidades, a de criar e programar um game.

Foram elaboradas quatro etapas as quais o docente deveria percorrer para completar sua jornada em todo o curso. Em cada uma das etapas citadas acima que compunham o curso (Figura 1), o participante deveria jogar o que denominamos "Quicks" e os "Loops de engajamento", contidos em cada uma das etapas e cujos campos teóricos em gamificação serão detalhados a seguir.

\subsubsection{Loops de engajamento}

Alguns dos principais elementos presentes nos jogos, tanto nos mais tradicionais (analógicos, físicos) como nos mais avançados (eletrônicos, digitais), emprestamos métodos e estratégias para propostas de gamificação.No curso gamificação que ora apresentamos usamos quatro alternativas para demonstração dos loops de engajamento, conforme mostra a figura 2.

Klock et. al. (2014) definem os loops de engajamento como elementos que se relacionam com a criação e manutenção das emoções motivadoras declaradas pelos jogadores, contribuindo para que estes se mantenham motivados e engajados com o ambiente do jogo tanto no momento atual quanto para fases posteriores.

\section{FIGURA 1 - Template Loops de engajamento}

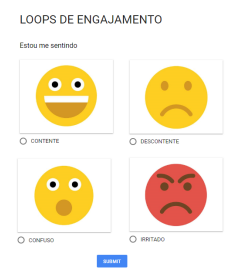




\subsubsection{Caixas Narrativas e Pontuação}

Dentre os vários elementos, destacamos a narrativa e a pontuação como elementos cruciais ao longo do curso gamificação. Uma missão bem definida em que a proposta da tarefa deva ser realizada para alcançar a vitória e a narrativa e a estratégia também bem definidas (níveis/fases) e que potencializem ao participante a capacidade de envolvimento com a história e aderência com as tarefas realizadas são fundamentais no delineamento de uma atividade gamificada (FARDO, 2013).

A pontuação é uma ferramenta invariável que compõe a maioria dos jogos. Faz parte então, daquilo que podemos denominar de "técnica de gamificação", o que corresponde a um dos paradigmas dos games. Em geral, os "pontos" são diretos e motivacionais e podem ser classificados em diferentes tipos.No curso gamificação criamos os "Quicks" que corresponderiam a "Pontos de Experiência", também conhecidos como "XP"(Experience points). Ou seja, todas as ações do jogador ao responder aos "Quicks" (independente da resposta correta dada) gerariam "pontos XP" durante o percurso no jogo. Isto significaria que o jogador sempre acumularia os pontos XP. Ao longo do curso havia 12 "Quicks", os quais possibilitariam 12 pontos "XP".

\section{3- Percurso metodológico}

Este artigo faz parte de uma pesquisa em andamento que envolve docentes de nível superior de ensino. Está ancorada na abordagem qualitativa (LUDKE; ANDRÉ, 1986), do tipo exploratória; o que implica estudo preliminar para maior familiarização com a temática investigada e adequação dos instrumentos de medida à realidade que se pretende conhecer (GIL, 1991). Os dados foram analisados a partir de métodos mistos, captando os respectivos pontos fortes de cada um (COFFIELD et al., 2004).

\subsection{Sujeitos e Procedimentos}

Todos os docentes da universidade foram convidados a participar da plataforma das trilhas de aprendizagem durante o $2^{\circ}$ semestre do ano de 2017. Os resultados obtidos se referem à participação dos profesores no curso gamificação no período de agosto a novembro do referido ano. Cada um dos participantes poderia se inscrever em um ou mais cursos (portfolio, sala de aula invertida e PBL) e fazê-los ao mesmo tempo. O curso apresenta uma estrutura de quatro etapas (no jogo intituladas de trechos), consideradas como fases para os jogadores. Em cada uma delas apresentávamos um loop de engajamento, totalizando 4 loops a serem respondidos pelos profesores. Quanto aos "quicks", três deles foram armazenados em cada um dos 4 trechos do curso gamificação, totalizando 12 "quicks". Neste trabalho, apresentaremos 6 "quicks" respondidos pelos docentes. Apresentamos, ainda, o delineamento de um curso de extensão de um docenteda instituição inspirado nos principios de gamificação. 


\section{4- Análise e discussão dos resultados}

Primeiramente apresentamos os dados quanto à frequência de respostas dos docentes quanto aos loops de engajamento e os "quicks" (pontos XP). Em seguida, apresentamos o delineamento da gamificação em curso de extensão.

\subsection{Resultados quanto aos loops de engajamento e os "quicks" (pontos xp)}

$\mathrm{Na}$ etapa de inscrição dos cursos, obtivemos 35 professores inscritos para participar do curso de Gamificação. Os participantes deveriam percorrer quatro trechos de loops de engajamento, declarando estarem: contentes, descontentes, confusos e irritados), conforme abordado acima.

\section{GRÁFICO 1 - Frequência de "loops de engajamento" declarados pelos docentes - Curso Gamificação}

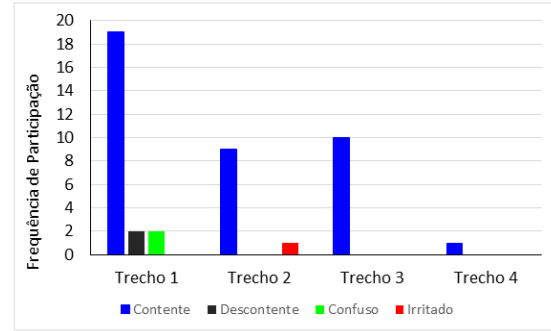

Logo no início do primeiro trecho, participaram 23(66\%) docentes que se declararam estarem $19(82 \%)$ contentes; $2(9 \%)$ descontentes e $2(9 \%)$ confusos. No Trecho 2, 10 $(29 \%)$ contentes participaram dos loops de engajamento, sendo que $9(90 \%)$ declararamse estar contentes e 1 (10\%) irritado. No trecho 3, 10 (29\%) professores participaram e todos se declararam contentes com o engajamento ao longo do curso. No Trecho 4 apenas 1 único sujeito participou e declarou estar contente.

Os dados nos fazem supor que o engajamento dos tipos "descontente e confuso" se manifestam apenas no início do curso o que pode indicar tipos de engajamento esperados dado que são docentes que estavam iniciando ineditamente o tema "gamificação", bem como a o recurso tecnológico em jogo.

GRÁFICO 2 - Frequência das respostas dos docentes na ferramenta "Quick" do Curso Gamificação

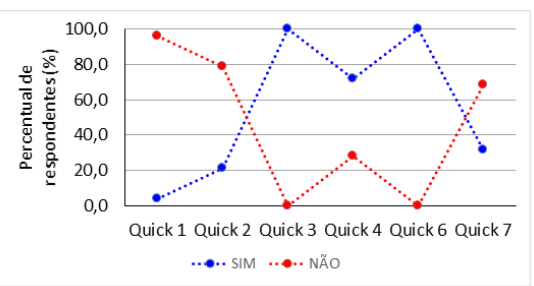


No trecho 1, três quicks foram apresentados, sendo o primeiro deles que perguntava ao jogador se, para ele, gamificação significava, apenas, usar jogos prontos na prática pedagógica. O segundo quick perguntava sobre a escolha do professor acerca do curso de gamificação quanto aos seus conhecimentos prévios sobre o tema.

No quick 1, 51 docentes participaram e no quick 2, 38 responderam (Gráfico 2). Em ambos os quicks, as respostas dominantes são negativas ao questionamento, mostrando-nos que a escolha não está diretamente ligada a um interesse mais pragmático dos docentes, ou seja, de aprender para usar diretamente com os alunos.

No trecho 2, o quick 4 perguntava ao docente se este havia escolhido o referido curso por se interessar em motivar mais seus alunos. Obtivemos 32 respostas e houve dominância para os "sins". Este dado pode nos permite aproximarmos das respostas dos quicks 1 e 2, pois, de um lado os docentes manifestam interesse sobre o tema, mas por outro, não se veem fazendo o curso apenas para aplicabilidade.

No trecho 3, quick 7 obtivemos 22 respondentes e a dominância foi negativa em relação à pergunta (você costuma dar desafios para seus alunos e pontuar para os que cumprem a tarefa?). Este dado nos parece indicar que embora considerem o tema motivador, relevante e adequado para o ensino universitário, ainda não dominam ferramentas específicas da lógica de games em situações não gamificadas para usarem como recurso para aprendizagem dos estudantes.

Os quicks 3 (trecho 1) e 6 (trecho 2) totalizaram 100\% de respostas positivas às perguntas que versavam sobre a possibilidade de uso dos princípios de gamificação para o ensino universitário e maior chance de provocar engajamento e motivação dos alunos.

\subsection{Resultados quanto ao delineamento de um curso de extensão voltado à gamificação}

O delineamento do projeto de extensão advindo da perspectiva da gamificação pode ser explicitado, conforme o que se segue. Os dados foram obtidos a partir do próprio projeto do docente que projetou o curso de extensão.

Introdução e Justificativa - A prática da extensão universitária é uma atividade de cunho social que visa proporcionar aos docentes e discentes a experiência de desenvolver uma série de conteúdos curriculares junto às comunidades. Os eixos temáticos que orientam o trabalho são o de Cultura e Comunicação, contido na Linha Temática 2: Cultura e Arte, da referida instituição. Projetos com foco em conteúdos audiovisuais para a infância e a adolescência são fundamentais na atuação do docente-Extensionistas, sobretudo com abrangência em gamificação.

Objetivos - Geral - Capacitar docentes e discentes de Escolas Estaduais de Ensino Médio de Campinas, a desenvolverem métodos de aprendizagem baseados nos 
princípios do Design e da Gamificação, com o intuito de ampliar a assimilação dos conteúdos formais abordados na grade curricular por meio da construção/experimentação de técnicas inovadoras de aprendizagem.

Específicos - Elaborar e colocar em prática, junto ao público envolvido no Projeto, jogos lúdicos baseados em temas transdisciplinares, como por exemplo "Sustentabilidade"; Capacitar o público envolvido no Projeto a transmitir os processos de elaboração de jogos e de materiais didáticos aos demais interessados que não tenham condições de participar diretamente das atividades.

Status do Curso de Extensão - Vigência de Março/2018 a janeiro/2020 (em desenvolvimento).

Participantes e Desenvolvimento - Três docentes e 25 alunos do $1^{\circ}$ e $2^{\circ}$ ano do Ensino Médio. As atividades do $1^{\circ}$ semestre de 2018 se referem à composição dos grupos de participantes, de reuniões para delineamento do escopo das atividades a serem desenvolvidas (criação e programação).

\section{5- Considerações finais}

A compreensão e aplicação de atividades gamificadas por docentes universitários podem ser uns dos caminhos para a ampliação das aprendizagens dos estudantes em plena era digital.

Os resultados obtidos mostram que, embora os docentes participantes demonstrassem estar engajados no curso e crerem que a gamificação possa ser mais uma alternativa para alavancar os processos de ensino e de aprendizagem na universidade; é preciso avançar no percentual de docentes concluintes do curso gamificação. Quanto à perda de participantes nos loops de engajamento e quicks, os resultados nos parecem indicar tal como apontado por Cerioni (2016) ao ser questionada sobre a dificuldade de se terminar um curso on-line. Aponta para o fato de que não existe um único motivo para as desistências, e sim, um conjunto de atitudes tanto do estudante quanto da escola que contribui para a abstenção do curso. Lembra que, segundo dados do Censo EAD/2015, as taxas de evasão para esta modalidade são, em média $50 \%$, ainda que a ideia de estudar sem sair de casa, na atualidade, seja um dos maiores atrativos.

Trilhas de Aprendizagem, contemplando o curso de gamificação evocam, no ambiente universitário, um caráter de inovação com dupla finalidade: como formação continuada dos docentes e na projeção de cursos de extensão em que se pesem a solidificação docência-extensão-pesquisa.

\section{Referências}

CERIONI, C. Não consegue concluir nenhum curso online? Este é o motivo. Exame. 2016.

Disponível

em: 
motivo-2/> Acesso em 20 jun.2017

COFFIELD, F.; MOSELEY, D.; HALL, E.;\& ECCLESTONE, K. Learning styles and Pedagogy in post-16 learning.A systematic and critical review. London: Learning and Skills Researche Centre, 2004.

CUNHA, R.C.O.B.;PRADO, G. do V. T. (2010). Formação centrada na escola, desenvolvimento pessoal e profissional de professores. Revista de Educação PUCCampinas, Campinas, n. 28, p.101-111, jan./jun. Disponível em http://periodicos.puccampinas.edu.br/seer/index.php/reveducacao/article/view/79.

FARDO, Marcelo Luis. A gamificação como método: Estudo de elementos dos games aplicados em Processos de ensino e aprendizagem. Dissertação (Mestrado em Educação) - Universidade de Caxias do Sul, Rio Grande do Sul, 2013.

GIL, A. C. Como classificar as pesquisas. In: GIL, A.C. Como elaborar projetos de pesquisa. São Paulo: Atlas, 1991. p. 45-62.

LUDKË, M.; ANDRÉ, M.E. A. D. Pesquisa em educação: abordagens qualitativas. São Paulo: EPU, 1986.

MARTINS, C.; GIRAFFA, L.M.M. Gamificação nas práticas pedagógicas: teorias, modelo e vivências. Nuevas ideas en informática educativa - TISE. 2015. Disponível em: http://www.tise.cl/volumen11/TISE2015/42-53.pdf. Acesso em: 30 nov.2016.

MATTAR, J. Games em educação: como os nativos digitais aprendem. São Paulo: Pearson Prentice Hall, 2010.

MEDINA, Bruno [et al.]. Gamification, Inc.: como reinventar empresas a partir de Jogos. Rio de Janeiro: MJV Press, 2013.

MCGONIGAL, Jane. Reality Is Broken: Why Games Make Us Better and How They Can Change the World. Nova York, Penguin Press, Ed. 1. 2011.

SALEN, Katie; ZIMMERMAN, Eric. Regras do Jogo - Fundamentos do Design de Jogos. Blucher, Vol. 1, Ed. 1. 2012.

UFMG. Universidade Federal de Minas Gerais. Plano Nacional de Extensão Universitária - editado. Coleção Extensão Universitária FORPROEX, vol. I. Disponível em:

$<$ https://www.ufmg.br/proex/renex/images/documentos/Plano-nacional-de-extensaouniversitaria-editado.pdf> Acesso em: 10 fev.2018. 